\title{
PARITAS DAN PERAN SERTA SUAMI DALAM PENGAMBILAN KEPUTUSAN TERHADAP PENGGUNAAN METODE KONTRASEPSI
}

\section{Parity and Role of Husband in Decision Making to Use Contraception Method}

\author{
Yeni, Rini Mutahar, Fenny Etrawati, Feranita Utama \\ Program Studi Ilmu Kesehatan Masyarakat Fakultas Kesehatan Masyarakat \\ Universitas Sriwijaya \\ (yenidoanks88@gmail.com)
}

\begin{abstract}
ABSTRAK
Data Riskesdas tahun 2013 menunjukkan prevalensi penggunaan KB yang meningkat dari 55,8\% pada tahun 2010 menjadi 59,7\% pada tahun 2013. Penelitian sebelumnya menunjukkan bahwa hanya 8,4\% pria menggunakan kontrasepsi atau terlibat secara langsung dalam penggunaan pelayanan keluarga berencana terutama kondom pria. Tujuan dari penelitian ini adalah mengetahui pengaruh paritas dan peran serta suami dalam pengambilan keputusan terhadap penggunaan metode kontrasepsi. Desain penelitian yang digunakan adalah desain cross sectional. Sampel penelitian ini adalah wanita menikah usia 15 - 45 tahun sebanyak 216 orang. Kriteria inklusi sampel adalah wanita dengan status menikah. Hasil penelitian menunjukkan sebanyak 79,2\% responden menggunakan kontrasepsi, 91,7\% responden memiliki suami yang mendukung kontrasepsi dan 72,7\% responden memiliki jumlah anak 2 sampai 4 orang. Ada pengaruh yang signifikan antara peran serta suami (PR:4,570;95\%CI:1,647-12,682) dan paritas (multipara (PR:0,218;95\%CI:0,060-0,790), primipara (PR:0,518;95\%CI:0,132-2,028)) terhadap penggunaan kontrasepsi. Hasil penelitian ini menunjukkan bahwa peran serta suami merupakan faktor risiko perilaku penggunaan metode kontrasepsi sedangkan paritas merupakan faktor protektif dari perilaku penggunaan metode kontrasepsi. Penelitian ini menunjukkan pentingnya mendorong para ibu rumah tangga untuk mengajak pasangan ikut serta dalam setiap pengambilan keputusan mengenai penggunaan metode kontrasepsi dengan meningkatkan cakupan partisipasi suami secara langsung dalam menggunakan metode kontrasepsi.
\end{abstract}

Kata kunci : Peran suami, paritas, kontrasepsi

\begin{abstract}
Riskesdas 2013 showed that contraceptive use prevalence increased from 55.8\% in 2010 to $59.7 \%$ in 2013. A previous research showed that only $8.4 \%$ of men use contraceptives or directly involved in family planning services use, especially condom. The purpose of this study was to determine the effect of parity and husband participation in decision making on contraceptive methods use. The study design used cross sectional design. Samples were married women aged 15-45 years as many as 216 people. The inclusion criteria were married women. The results showed $79.2 \%$ of respondents using contraception, $91.7 \%$ of respondents have a supportive husband in contraception and $72.7 \%$ of respondents had a number of children 2 to 4 people. There was a significant relationship between the husband role (PR:4.570 (95\% CI: 1.647 to 12.682) and parity (multiparous (PR: 0,218 (95\% CI: 0,060 - 0,790)), grandemultipara (PR: 0.518 (95\% CI: 0.132 to 2.028)) towards the contraceptives use. The result showed that the husband role is a risk factor while parity a protective factor of the contraceptive method behavior. This study showed the importance of encouraging housewives to suggest spouse participation in decision making about contraception use by increasing the scope of husband direct participation.
\end{abstract}

Keywords : The role of husband, parity, contraception 


\section{PENDAHULUAN}

Hasil proyeksi penduduk memperlihatkan bahwa laju pertumbuhan penduduk mencapai $1,40 \%$, per tahun. ${ }^{1}$ Jika tidak dilakukan upaya pengendalian penduduk, dapat berdampak pada potensi terjadinya ledakan penduduk di masa akan datang. Hal ini terlihat dari adanya kenaikan angka kelahiran kasar di Indonesia dari 17,4\% per 1000 penduduk pada tahun 2000 menjadi 17,9 kelahiran per 1000 penduduk pada tahun $2010 .^{2}$ Oleh karena itu, ditetapkanlah sebuah kebijakan melalui program keluarga berencana dalam mewujudkan penduduk tumbuh seimbang dan keluarga yang berkualitas sesuai dengan amanat dari Undang-Undang Republik Indonesia Nomor 52 Tahun 2009 tentang perkembangan kependudukan dan pembangunan keluarga. ${ }^{3}$

Data Riskesdas tahun 2013 menunjukkan prevalensi penggunaan $\mathrm{KB}$ yang meningkat dari $55,8 \%$ pada tahun 2010 menjadi $59,7 \%$ pada tahun 2013. Sebanyak 59,3\% dari total pengguna KB menggunakan metode kontrasepsi modern dan $0,4 \%$ adalah metode kontrasepsi tradisional. Metode kontrasepsi yang paling banyak digunakan oleh wanita usia subur berstatus kawin adalah metode suntik yaitu $34.4 \% .{ }^{4}$ Penelitian sebelumnya menunjukkan bahwa hanya $8,4 \%$ pria menikah yang berpartisipasi secara langsung dalam penggunaan kontrasepsi dengan menggunakan kondom. ${ }^{5}$

Perempuan yang berusia kurang dari 20 tahun, jumlah anak kurang dari atau sama dengan dua, pendidikan yang rendah, dan perempuan yang melakukan persalinan di rumah paling be- risiko untuk mengalami unmet need. ${ }^{6}$ Persetujuan suami terhadap keluarga berencana adalah faktor protektif kejadian unmet need untuk metode kontrasepsi modern $(\mathrm{OR}=0,858 ; \mathrm{CI}=0,756-0,975 ; \mathrm{p}=0,019){ }^{7}$ Palamuleni dalam penelitiannya menunjukkan bahwa faktor utama yang mempengaruhi penggunaan metode kontrasepsi adalah usia, persetujuan pasangan mengenai program keluarga berencana, diskusi dengan pasangan, jumlah anak yang hidup, status pekerjaan, pendidikan dan kunjungan ke pusat kesehatan. ${ }^{8}$

Fertilitas dan keterlibatan suami adalah determinan yang paling penting dalam hal penggunaan metode kontrasepsi pasangan. ${ }^{9}$ Pendapat mengenai pelayanan keluarga berencana, persetu- juan dari laki-laki dan metode kontrasepsi yang sedang digunakan berhubungan dengan keterlibatan laki-laki dalam pemanfaatan pelayanan keluarga berencana. ${ }^{5}$ Berdasarkan dukungan pasangan, masih banyak perempuan yang merasa gugup untuk mendiskusikan metode kontrasepsi dengan suaminya baik pada perempuan dengan tingkat paritas rendah maupun paritas tinggi $(67,9 \%$ dan $64,2 \%) .{ }^{10}$ Penelitian ini bertujuan untuk mengetahui hubungan peran serta suami dalam pengambilan keputusan dan paritas terhadap penggunaan metode kontrasepsi.

\section{BAHAN DAN METODE}

Penelitian menggunakan pendekatan analitik kuantitatif dengan desain penelitian cross sectional. Lokasi penelitian di wilayah Inderalaya Kabupaten Ogan Ilir. Responden penelitian adalah ibu rumah tangga dengan status menikah yang berdomisili tetap di wilayah Inderalaya Kabupaten Ogan Ilir. Teknik pengambilan sampel dilakukan menggunakan metode multistage random sampling. Tahap pertama dilakukan pemilihan cluster. Cluster yang digunakan pada penelitian ini adalah kecamatan. Setelah dilakukan random terhadap semua kecamatan, diperoleh Kecamatan Tanjung raja, Indralaya dan Indralaya Selatan sebagai cluster penelitian. Setiap cluster di ambil dua desa. Tahap selanjutnya adalah melakukan pemilihan unit sampling (rumah tangga) pada setiap cluster/ kecamatan terpilih menggunakan metode simple random sampling. Besar sampel minimal dikali desain efek sebesar dua (2) agar dapat mewakili karakteristik responden dari cluster yang tidak terpilih. Besar sampel minimal masing-masing desa dialokasikan sama. Berdasarkan hasil perhitungan, besar sampel minimal yang digunakan adalah 216 responden. Besar sampel minimal yang diambil di tiap desa adalah 36 responden.

Analisis data yang dilakukan meliputi analisis univariat, bivariat dan multivariat. Analisis univariat digunakan untuk mendeskripsikan variabel independen dan variabel dependen. Analisis bivariat dilakukan untuk mengetahui ada tidaknya hubungan antara dua variabel yaitu variabel independen dengan variabel dependen. Uji statistik yang digunakan adalah uji chi-Square dengan derajat kemaknaan $(\alpha)$ sebesar $5 \%$. Selain itu, dalam penelitian ini akan dilakukan perhitungan Rasio 
Prevalensi (RP). Analisis multivariat bertujuan untuk menganalisis pengaruh paritas dan peran serta suami dalam pengambilan keputusan dengan penggunaan kontrasepsi. Uji statistik yang digunakan untuk analisis multivariat ini adalah regresi

Tabel 1. Gambaran Karakteristik Responden

\begin{tabular}{|c|c|}
\hline Karakteristik & $n=170(\%)$ \\
\hline \multicolumn{2}{|l|}{ Pendidikan } \\
\hline Rendah $(\leq \mathrm{SMP})$ & 51,9 \\
\hline Tinggi ( $\geq \mathrm{SMA})$ & 48,1 \\
\hline \multicolumn{2}{|l|}{ Jarak Kelahiran } \\
\hline Lebih dari setahun & 71,8 \\
\hline Kurang dari setahun & 28,2 \\
\hline \multicolumn{2}{|l|}{ Sosial ekonomi } \\
\hline Rendah (<UMR) & 80,1 \\
\hline Tinggi ( $\geq$ UMR) & 19,9 \\
\hline \multicolumn{2}{|l|}{ Cara persalinan } \\
\hline Normal & 87 \\
\hline Caesar & 13 \\
\hline \multicolumn{2}{|l|}{ ANC } \\
\hline Tidak lengkap & 8,3 \\
\hline Lengkap & 91,7 \\
\hline \multicolumn{2}{|l|}{ Tempat persalinan } \\
\hline Non fasilitas kesehatan & 19,4 \\
\hline Fasilitas kesehatan & 80,6 \\
\hline \multicolumn{2}{|l|}{ Tenaga penolong persalinan } \\
\hline Non tenaga kesehatan & 4,6 \\
\hline Tenaga kesehatan & 95,4 \\
\hline \multicolumn{2}{|l|}{ Pengetahuan } \\
\hline Kurang baik & 35,2 \\
\hline Baik & 64,8 \\
\hline \multicolumn{2}{|l|}{ Problem solving } \\
\hline Tidak baik & 33,8 \\
\hline Baik & 66,2 \\
\hline \multicolumn{2}{|c|}{ Akses terhadap sumber informasi } \\
\hline Tidak ada & 32,4 \\
\hline Ada & 67,6 \\
\hline \multicolumn{2}{|l|}{ Perceived control } \\
\hline Negatif & 48,6 \\
\hline Positif & 51,4 \\
\hline \multicolumn{2}{|l|}{ Peran serta suami } \\
\hline Kurang mendukung & 8,3 \\
\hline Mendukung & 91,7 \\
\hline \multicolumn{2}{|l|}{ Paritas } \\
\hline Primipara & 22,2 \\
\hline Multipara & 72,7 \\
\hline Grandemultipara & 5,1 \\
\hline \multicolumn{2}{|l|}{ Penggunaan kontrasepsi } \\
\hline Tidak & 20,8 \\
\hline Ya & 79,2 \\
\hline
\end{tabular}

Sumber : Data Primer, 2016 logistik ganda model faktor risiko. Penyajian data menggunakan tabel dan dinarasikan. Variabel dependen pada penelitian ini adalah perilaku penggunaan metode kontrasepsi. Variabel independen utama pada penelitian ini adalah peran serta suami dan paritas, sedangkan variabel yang dikontrol adalah umur, pendidikan responden, status ekonomi, jarak kelahiran, cara melahirkan, tempat persalinan, ANC, pengetahuan, problem solving abilities, sumber informasi, dan perceived control.

\section{HASIL}

Hasil analisis diperoleh bahwa sebanyak $51,9 \%$ responden berpendidikan rendah, terdapat $71,8 \%$ memiliki jarak kelahiran lebih dari setahun, $80,1 \%$ memiliki status ekonomi rendah, $87 \%$ melakukan persalinan terakhir secara normal, 91,7\% memiliki ANC lengkap (satu kali trimester pertama, satu kali trimester kedua dan dua kali trimester ketiga), 80,6\% melakukan persalinan di fasilitas kesehatan, 95,4\% melakukan persalinan ditolong oleh tenaga kesehatan, $64,8 \%$ memiliki pengetahuan baik, 66,2\% memiliki problem solving ability yang baik, $67,6 \%$ memiliki akses terhadap sumber informasi, 51,4\% memiliki perceived control yang positif, $91,7 \%$ memiliki peran suami yang mendukung, dan $72,7 \%$ memiliki anak lebih dari satu (multipara) (Tabel 1).

Hasil analisis statistik menggunakan uji chi square diperoleh dua belas variabel independen tidak memiliki hubungan yang bermakna secara statistik yaitu tingkat pendidikan, jarak kelahiran, sosial ekonomi, cara persalinan, ANC, tempat persalinan, tenaga penolong persalinan, pengetahuan, problem solving ability, akses terhadap sumber informasi dan perceived control $(\mathrm{p}>0,05)$. Ditinjau dari peran serta suami, diketahui adanya hubungan yang bermakna secara statistik terhadap penggunaan metode kontrasepsi $(\mathrm{p}=0,004)$. Berdasarkan paritas diketahui adanya hubungan yang bermakna secara statistik terhadap penggunaan metode kontrasepsi $(\mathrm{p}=0,009)($ Tabel 2).

Hasil analisis multivariat diperoleh bahwa variabel yang memiliki pengaruh paling besar terhadap penggunaan metode kontrasepsi adalah peran serta suami (RP:4,570; 95\% CI: 1,647-12,682). Responden dengan peran serta suami yang kurang mendukung berpeluang 4,5 kali lebih besar untuk tidak menggunakan metode kontrasepsi diban- 
Tabel 2. Distribusi Faktor Risiko Penggunaan Metode Kontrasepsi

\begin{tabular}{|c|c|c|c|c|c|}
\hline \multirow{3}{*}{ Variabel } & \multicolumn{4}{|c|}{ Penggunaan Metode Kontrasepsi } & \multirow{3}{*}{$\mathbf{p}$} \\
\hline & \multicolumn{2}{|c|}{ Tidak } & \multicolumn{2}{|c|}{ Ya } & \\
\hline & $\mathbf{n}$ & $\%$ & $\mathbf{n}$ & $\%$ & \\
\hline \multicolumn{6}{|l|}{ Pendidikan } \\
\hline Rendah $(\leq \mathrm{SMP})$ & 20 & 17,9 & 92 & 82,1 & 0,342 \\
\hline Tinggi ( $\geq \mathrm{SMA})$ & 25 & 24 & 79 & 76 & \\
\hline \multicolumn{6}{|l|}{ Jarak Kelahiran } \\
\hline Lebih dari setahun & 26 & 16,8 & 129 & 83,2 & 0,031 \\
\hline Kurang dari setahun & 19 & 31,1 & 42 & 68,9 & \\
\hline \multicolumn{6}{|l|}{ Sosial ekonomi } \\
\hline Rendah (<UMR) & 34 & 19,7 & 139 & 80,3 & 0,518 \\
\hline Tinggi ( $\geq$ UMR) & 11 & 25,6 & 32 & 74,4 & \\
\hline \multicolumn{6}{|l|}{ Cara persalinan } \\
\hline Normal & 38 & 20,2 & 150 & 79,8 & 0,739 \\
\hline Caesar & 7 & 25 & 21 & 75 & \\
\hline \multicolumn{6}{|l|}{ ANC } \\
\hline Tidak lengkap & 5 & 27,8 & 13 & 72,2 & 0,543 \\
\hline Lengkap & 40 & 20,2 & 158 & 79,8 & \\
\hline \multicolumn{6}{|l|}{ Tempat persalinan } \\
\hline Non fasilitas kesehatan & 8 & 19 & 34 & 81 & 0,916 \\
\hline Fasilitas kesehatan & 37 & 21,3 & 137 & 78,7 & \\
\hline \multicolumn{6}{|l|}{ Tenaga penolong persalinan } \\
\hline Non tenaga kesehatan & 3 & 30 & 7 & 70 & 0,438 \\
\hline Tenaga kesehatan & 42 & 20,4 & 164 & 79,6 & \\
\hline \multicolumn{6}{|l|}{ Pengetahuan } \\
\hline Kurang baik & 13 & 17,1 & 63 & 82,9 & 0,413 \\
\hline Baik & 32 & 22,9 & 108 & 77,1 & \\
\hline \multicolumn{6}{|l|}{ Problem solving } \\
\hline Tidak baik & 16 & 21,9 & 57 & 78,1 & 0,918 \\
\hline Baik & 29 & 20,3 & 114 & 79,7 & \\
\hline \multicolumn{6}{|c|}{ Akses terhadap sumber informasi } \\
\hline Tidak ada & 18 & 25,7 & 52 & 74,3 & 0,296 \\
\hline Ada & 27 & 18,5 & 119 & 81,5 & \\
\hline \multicolumn{6}{|l|}{ Perceived control } \\
\hline Negatif & 19 & 18,1 & 86 & 81,9 & 0,426 \\
\hline Positif & 26 & 23,4 & 85 & 76,6 & \\
\hline \multicolumn{6}{|l|}{ Peran serta suami } \\
\hline Kurang mendukung & 9 & 50 & 9 & 50 & 0,004 \\
\hline Mendukung & 36 & 18,2 & 162 & 81,8 & \\
\hline \multicolumn{6}{|l|}{ Paritas } \\
\hline Primipara & 15 & 31,2 & 33 & 68,8 & 0,009 \\
\hline Multipara & 25 & 32,7 & 132 & 84,1 & \\
\hline Grandemultipara & 5 & 45,4 & 6 & 54,5 & \\
\hline
\end{tabular}

Sumber : Data Primer, 2016

dingkan responden dengan peran serta suami yang mendukung. Di populasi umum, peneliti $95 \%$ yakin bahwa peran serta suami adalah faktor risiko penggunaan metode kontrasepsi dengan rentang interval 1,647 sampai 12,682). Ditinjau dari varia- bel paritas, hasil penelitian menunjukkan bahwa responden yang memiliki anak lebih dari satu (multipara) berpeluang 0,218 lebih kecil untuk tidak menggunakan metode kontrasepsi dibandingkan responden yang memiliki anak lebih dari 
4 (grandemultipara) (Tabel 3).

\section{PEMBAHASAN}

Mayoritas responden memiliki peran serta suami yang kurang mendukung dalam hal penggunaan metode kontrasepsi. Sebagian dari responden dengan peran serta suami yang kurang mendukung ternyata tidak menggunakan metode kontrasepsi. Hasil penelitian ini menunjukkan bahwa responden dengan peran serta suami yang kurang mendukung berpeluang 4,5 kali untuk tidak menggunakan metode kontrasepsi dibandingkan responden dengan peran serta suami yang mendukung. Rendahnya partisipasi pasangan dalam penggunaan metode kontrasepsi antara lain disebabkan oleh keinginan pasangan untuk memiliki anak lagi, penolakan dari istri atau pasangan itu sendiri, ketakutan akan efek samping, dilarang oleh agama, kurangnya kesadaran mengenai kontrasepsi dan pemikiran bahwa kontrasepsi adalah masalah perempuan. ${ }^{5}$

Hambatan terbesar perempuan dalam menggunakan kontrasepsi adalah kepercayaan mereka bahwa keputusan mengenai metode kontrasepsi dilakukan oleh suami dan kesuburan ditentukan oleh Tuhan. ${ }^{11}$ Penelitian sebelumnya menunjukkan bahwa ada hubungan yang bermakna secara statistik antara pengambilan keputusan secara bersama-sama dalam rumah tangga terhadap penggunaan metode kontrasepsi yang melibatkan pasangan meliputi kondom pria, withdrawal dan pantang berkala $(\mathrm{OR}=1,29,95 \% \mathrm{CI}: 1,15-1,44) .{ }^{12}$

Mayoritas responden pada kelompok dengan peran serta suami yang mendukung menggunakan metode kontrasepsi dan hanya sebagian kecil yang tidak menggunakan metode kontrasepsi. Hal ini menunjukkan bahwa semakin baik dukungan pasangan dalam rumah tangga maka akan semakin meningkatkan prevalensi pengggunaan metode kontrasepsi. Responden yang berdiskusi dengan pasangannya mengenai kontrasepsi akan berisiko lebih besar untuk menggunakan metode kontrasepsi dibanding responden yang tidak berdiskusi dengan pasangannya $(\mathrm{OR}=4,67 ; 95 \% \mathrm{CI}: 2,88-7,58) .{ }^{13}$ Penelitian Rizali et al., menunjukkan adanya hubungan yang signifikan antara kesepakatan suami dan istri dengan penggunaan metode kontrasepsi suntik. ${ }^{14}$ Dukungan pasangan tidak hanya melalui dukungan tidak langsung seperti diskusi namun dapat berupa dukungan langsung dengan menggunakan metode kontrasepsi tertentu. Penelitian sebelumnya menyatakan bahwa sebesar $8,4 \%$ pria menggunakan metode kontrasepsi atau berpartisipasi langsung dalam penggunaan metode

Tabel 3. Analisis Multivariat Peran Serta Suami dan Paritas terhadap Penggunaan Metode Kontrasepsi

\begin{tabular}{lcccccc}
\hline \multirow{2}{*}{ Variabel } & \multicolumn{3}{c}{ Model Awal } & \multicolumn{3}{c}{ Model Akhir } \\
\cline { 2 - 7 } & $\begin{array}{c}\text { RP } \\
\text { Crude }\end{array}$ & $\mathbf{9 5 \%}$ CI & p value & $\begin{array}{c}\text { RP } \\
\text { Adjusted }\end{array}$ & $\mathbf{9 5 \%}$ CI & p value \\
\hline Peran serta suami & 5,375 & $1,858-15,547$ & 0,002 & 4,570 & $1,647-12,682$ & 0,004 \\
Paritas & & & & & & \\
Multipara & 0,603 & $0,032-0,603$ & 0,138 & 0,218 & $0,060-0,790$ & 0,020 \\
Primipara & 1,785 & $0,040-1,785$ & 0,267 & 0,518 & $0,132-2,028$ & 0,345 \\
Pendidikan & 0,566 & $0,264-1,212$ & 0,143 & & & \\
Jarak Kelahiran & 0,670 & $0,163-2,757$ & 0,579 & & & \\
Sosial ekonomi & 0,497 & $0,197-1,250$ & 0,137 & & & \\
Cara persalinan & 1,521 & $0,501-4,617$ & 0,459 & & & \\
ANC & 0,993 & $0,284-3,472$ & 0,992 & & & \\
Tempat persalinan & 0,804 & $0,282-2,290$ & 0,683 & & & \\
Tenaga penolong persalinan & 2,744 & $0,484-15,540$ & 0,254 & & & \\
Pengetahuan & 0,610 & $0,270-1,378$ & 0,235 & & & \\
Problem solving & 0,952 & $0,429-2,112$ & 0,904 & & & \\
Akses terhadap sumber informasi & 1,641 & $0,751-3,584$ & 0,214 & & & \\
Perceived control & 0,742 & $0,351-1,567$ & 0,433 & & & \\
\hline
\end{tabular}

Sumber : Data Primer, 2016 
kontrasepsi terutama kondom pria. ${ }^{5}$

Lebih dari sebagian responden merupakan ibu rumah tangga pada kelompok paritas multipara. Hampir sebagian dari responden yang memiliki anak lebih dari 4 (grandemultipara) tidak menggunakan metode kontrapsepsi. Hasil penelitian ini menunjukkan bahwa ada hubungan yang bermakna secara statistik antara paritas dan penggunaan metode kontrasepsi. Hal ini sejalan dengan penelitian sebelumnya yang menyatakan ada hubungan yang signifikan antara paritas dan penggunaan metode kontrasepsi (OR:3,2;95\%CI:1,5-6,7) ${ }^{15}$ Responden yang memiliki anak lebih dari satu berpeluang 0,2 kali lebih kecil untuk tidak menggunakan metode kontrasepsi dibandingkan responden yang memiliki anak lebih dari 4 orang, sedangkan responden yang memiliki paritas satu orang anak (primipara) berisiko 0,5 kali lebih rendah untuk tidak menggunakan metode kontrasepsi dibandingkan responden dengan paritas lebih dari empat orang (grandemultipara).

Responden yang memiliki anak kurang dari atau sama dengan 2 akan lebih berisiko untuk mengalami unmeet need $\mathrm{KB}$ dibandingkan mereka yang memiliki anak lebih dari dua orang. ${ }^{6}$ Mayoritas responden yang memiliki anak lebih dari satu (multipara) menggunakan metode kontrasepsi dan hanya sebagian kecil yang tidak menggunakan metode kontrasepsi. Semakin banyak jumlah anak yang dimiliki akan meningkatkan kecenderungan seseorang untuk menggunakan metode kontrasepsi tertentu. Penggunaan metode kontrasepsi mengalami penurunan pada kelompok paritas lebih dari 4 orang. Hal tersebut dapat terjadi karena responden dengan paritas lebih dari 4 orang cenderung telah melewati usia reproduksi yang baik untuk hamil atau berada di atas 30 tahun. Godfrey dalam penelitiannya menyatakan bahwa perempuan yang mengalami kehamilan yang tidak diinginkan pada usia di atas 35 tahun cenderung melaporkan adanya anggapan bahwa mereka memiliki risiko yang lebih rendah untuk mengalami kehamilan dan pengalaman masa lalu dengan efek samping yang tidak diinginkan dari metode kontrasepsi. ${ }^{16}$

Hasil analisis statistik diperoleh variabel independen yang tidak memiliki hubungan bermakna secara statistik adalah tingkat pendidikan, jarak kelahiran, sosial ekonomi, cara persalinan, ANC, tempat persalinan, tenaga penolong persa- linan, pengetahuan, problem solving ability, akses terhadap sumber informasi dan perceived control $(\mathrm{p}>0,05)$. Hal ini dimungkinkan karena sebagian besar responden tidak mendapat dukungan yang cukup dari suami dalam hal penggunaan metode kontrasepsi. Ditinjau dari kemampuan responden dalam menyelesaikan masalah juga diketahui bahwa sebagian dari responden mempunyai problem solving ability yang kurang baik. Selain itu mayoritas responden diketahui berasal dari rumah tangga dengan status sosial ekonomi yang rendah. Perempuan akan memiliki kekuatan yang besar dalam pengambilan keputusan seiring meningkatnya usia, tingkat pendidikan, jumlah anak atau pada status sosial ekonomi yang tinggi Pengambilan keputusan secara bersama adalah determinan yang paling kuat dalam penggunaan metode kontrasepsi dibandingkan pengambilan keputusan sendiri. ${ }^{12}$

\section{KESIMPULAN DAN SARAN}

Hasil analisis menunjukkan bahwa peran serta suami merupakan faktor risiko perilaku penggunaan metode kontrasepsi sedangkan paritas merupakan faktor protektif dari perilaku penggunaan metode kontrasepsi. Pentingnya mendorong para ibu rumah tangga untuk mengajak pasangan ikut serta dalam setiap pengambilan keputusan mengenai penggunaan metode kontrasepsi. Hal ini dapat dilakukan dengan meningkatkan cakupan partisipasi suami secara langsung dalam menggunakan metode kontrasepsi tertentu terutama pada kelompok multipara. Selain itu, diperlukan adanya penelitian lebih lanjut pada kelompok suami itu sendiri untuk melihat faktor yang mempengaruhi peran serta atau partisipasi mereka dalam penggunaan metode kontrasepsi.

\section{DAFTAR PUSTAKA}

1. BPS. Statistik Indonesia 2015. Indonesia: Badan Pusat Statistik; 2015.

2. BKKBN. Direktorat Perencanaan Pengendalian Penduduk dengan Pusat Penelitian dan Pengembangan Kependudukan. Profil Kependudukan dan Pembangunan di Indonesia. Jakarta: BKKBN; 2013

3. Undang - Undang Republik Indonesia Nomor 52 tahun 2009 tentang Perkembangan Kependudukan dan Pembangunan Keluarga. 2009.

4. Kemenkes RI. Riset Kesehatan Dasar 2012. 
Badan Penelitian dan Pengembangan Kesehatan: Jakarta: Kementerian Keseharan RI; 2013.

5. Kassa et al. Level of Male Involvement and Associated Factors in Family Planning Services Utilization among Married Men in Debremarkos Town, Northwest Ethiopia. BMC International Health and Human Rights. 2014; 14(33).

6. Pasha et al. Postpartum Contraceptive Use and Unmeet Need for Family Planning in Five Low Income Countries. Reproductive Health Journal. 2015;12(suppl 2): S11.

7. Adebowale, S.A \& Palamuleni, M.E. Determinants of Unmeet Need for Modern Contraception and Reason for Non Use among Married Women in Rural Areas of Burkina Faso. African Population Studies [Online Journal]. 2014; 28(1).

8. Palamuleni, M. E. Determinants of Contraceptive Choices in Malawi. Romanian Journal of Population Studies [Online Journal]. 2015; 9(1):49-79.

9. Hailed dan Enqueselassie. Influence of Women's Autonomy on Couple's Contraception Use in Jimma town, Ethiopia. Ethiopian Journal of Health Development. 2006;20(3):145151

10. Samandari et al. The Role of Social Support and Parity on Contraceptive Use in Cambodia. International Perspectives on Sexual and Reproductive Health. 2010;36(3):122-131.

11. Agha, sohail. Intentions to Use Contraceptives in Pakistan: Implications for Behavior Change Campaigns. BMC Public Health. 2010;10(450).

12. Hameed W, Azmat SK, Ali M, Sheikh MI, Abbas G, Temmerman M, et al. Women's Empowerment and Contraceptive Use: The Role of Independent versus Couples' Decision-Making, from a Lower Middle Income Country Perspective. PLoS ONE. 2014;9(8).

13. Elliason et al. Determinants of Modern Family Planning Use among Women of Reproductive Age in the Nkwanta. Reproductive Health Journal. 2014;11(65).

14. Rizali et al. Faktor yang Berhubungan dengan Pemilihan Metode Kontrasepsi Suntik di Kelurahan Mattoangin Kecamatan Mariso Kota Makassar. Media kesehatan masyarakat Indonesia. 2013;9(3)

15. Ali et al. Use of Family Planning Methods in Kassala, Eastern Sudan. BMC Research Notes. 2011;4(43).

16. Godfrey et al. Contraceptive Methods and Use by Women Aged 35 and Over: A Qualitative Study of Perspectives. BMC Women'n Health. 2011;11(5). 